\title{
Fourth Cranial Nerve Palsy and Brown Syndrome: Two Interrelated Congenital Cranial Dysinnervation Disorders?
}

\author{
Pierre-François Kaeser • Michael C. Brodsky
}

Published online: 1 May 2013

(C) Springer Science+Business Media New York 2013

\begin{abstract}
Based on neuroimaging data showing absence of the trochlear nerve, congenital superior oblique palsy is now classified as a congenital cranial dysinnervation disorder. A similar absence of the abducens nerve is accompanied by misinnervation to the lateral rectus muscle from a branch of oculomotor nerve in the Duane retraction syndrome. This similarity raises the question of whether some cases of Brown syndrome could arise from a similar synkinesis between the inferior and superior oblique muscles in the setting of congenital superior oblique palsy. This hypothesis has gained support from the confluence of evidence from a number of independent studies. Using Duane syndrome as a model, we critically review the accumulating evidence that some cases of Brown syndrome are ultimately attributable to dysgenesis of the trochlear nerve.
\end{abstract}

Keywords Trochlear palsy $\cdot$ Fourth nerve palsy $\cdot$ Superior oblique palsy $\cdot$ Brown syndrome $\cdot$ Congenital cranial dysinnervation disorder · CCDD · Misinnervation . Synkinesis $\cdot$ Oculomotor nerve $\cdot$ Third nerve $\cdot$ Trochlear nerve $\cdot$ Fourth nerve $\cdot$ Abducens nerve $\cdot$ Sixth nerve $\cdot$ Duane syndrome

\section{Introduction}

Over the past 3 decades, many congenital ocular motility disorders that were formerly considered to result from

This article is part of the Topical Collection on Neuro-ophthalmology

P.-F. Kaeser $(\triangle)$

Jules Gonin Eye Hospital, University of Lausanne, Avenue de France 15,

1004 Lausanne, Switzerland

e-mail: pierre-francois.kaeser@fa2.ch

M. C. Brodsky

Departments of Ophthalmology and Neurology, Mayo Clinic,

Rochester, MN, USA primary abnormalities of extraocular muscle or orbital tissue development [1-4], have been shown to result from abnormal neuronal development. In 2003, Gutowski et al assigned the term congenital cranial dysinnervation disorders (CCDDs) to these conditions that share the common features of dysinnervation to the ocular and facial musculature $[5-7,8 \cdot, 9,10]$. In most of these disorders, absent or deficient innervation results in extraocular muscle hypoplasia and fibrosis causing limitation and restriction of ocular rotations. In addition, neuronal misinnervation frequently develops and induces distinctive combinations of synkinetic eye movements (Table 1).

\section{Duane Syndrome as a Prototypical CCDD}

To examine the interrelationship between congenital fourth nerve palsy and Brown syndrome, it is instructive to briefly review the evolution in our understanding of Duane retraction syndrome, the prototypical CCDD. Duane retraction syndrome is a congenital ocular motility disorder that arises from deficient abducens innervation to the lateral rectus muscle causing anomalous innervation from the medial rectus muscle. This anomalous innervation produces cocontraction of both horizontal rectus muscles and a striking retraction of the globe on attempted adduction. In contrast to Duane syndrome, isolated congenital abducens palsy is exceptionally rare [11], attesting to strong tendency of neuronal misdirection to develop during embryogenesis when developing neurons fail to form normal connections at their target sites within the extraocular muscles. These rare cases of congenital sixth palsy that fail to develop misinnervation could result from the absence or hypoplasia of the abducens nerve fascicle and thus also fall into the classification of CCDD $[6,7]$.

Duane retraction syndrome purportedly accounts for $1 \%-4 \%$ of strabismus cases $[9,12]$. As with various other conditions such as congenital fibrosis of extraocular muscles and congenital ptosis now classified as CCDDs, Duane 
Table 1 Congenital cranial dysinnervation disorders (CCDD) (modified from $[6,7]$ )

\begin{tabular}{|c|c|c|}
\hline \multicolumn{3}{|c|}{ Congenital cranial dysinnervation disorders } \\
\hline \multirow[t]{2}{*}{ Involved cranial nerve } & Eye motility limitation with lack of innervation & \\
\hline & Without synkinetic eye movement & With synkinetic eye movement \\
\hline \multirow[t]{2}{*}{ VI } & $\begin{array}{l}\text { - Congenital } \mathrm{VI}^{\text {th }} \text { nerve palsy } \\
\text { - Horizontal gaze palsy with progressive scoliosis (HGPPS) }\end{array}$ & • Duane syndrome \\
\hline & • Möbius sequence & \\
\hline \multirow[t]{4}{*}{ III } & - Congenital III ${ }^{\text {th }}$ nerve palsy & • Marcus Gunn jaw winking \\
\hline & - Double elevator palsy & $\begin{array}{l}\text { - Congenital fibrosis of the extraocular } \\
\text { muscles (CFEOM) }\end{array}$ \\
\hline & - Congenital ptosis & $\begin{array}{l}\text { - Congenital III }{ }^{\text {th }} \text { nerve palsy with ocular } \\
\text { motor synkinesis }\end{array}$ \\
\hline & & - Vertical retraction syndrome \\
\hline \multirow[t]{4}{*}{ IV } & - Congenital IV ${ }^{\text {th }}$ nerve palsy & - Congenital Brown syndrome \\
\hline & Ocular motor synkinesis without lack of innervation & \\
\hline & • Coinnervation between III, IV, VI & \\
\hline & - Coinnervation between III, IV, VI, and V, VII, IX, XII & \\
\hline
\end{tabular}

syndrome was initially thought to result from a primary maldevelopment of the rectus muscles, eg, posterior insertion of the medial rectus muscle $[13,14]$ or primary fibrosis of the lateral rectus muscle [15]. In 1956, Hoyt and Nachtigael first proposed that Duane syndrome could result from the compensatory innervation to a paretic lateral rectus muscle by an extra branch of the third cranial nerve, causing co-contraction of both horizontal rectus muscles [16]. This theory was supported by electromyographic studies confirming the presence of paradoxical innervation of the lateral rectus muscle [17]. The neurodevelopmental origin of Duane syndrome was subsequently proven by histopathologic studies, which showed absence of the sixth cranial nerve, hypoplasia of the corresponding portion of the abducens nucleus, and misinnervation of the lateral rectus muscle from fibers of the third cranial nerve [18-20]. Lateral rectus muscle bundles were normal in areas innervated by fibers from the third cranial nerve, whereas the remaining muscle was fibrotic $[19,20]$. In contradistinction to Möbius sequence, which requires abnormal development at the level of the abducens nucleus to produce the observed horizontal conjugate gaze palsy, a dysgenesis involving the abducens nerve fascicle is necessary to explain preservation of crossed medial rectus motor neurons in Duane syndrome [11, 21•]. Unlike other CCDDs [22], orbital magnetic resonance (MR) imaging has shown the size of the lateral rectus muscle to be normal in Duane syndrome, likely due to trophic effects of anomalous innervation of the third nerve [12]. Dynamic orbital MR imaging studies have further shown that the diameter of the lateral rectus muscle remains constant in adduction and abduction, reflecting the fact that it does not relax during adduction as it should [12]. At a higher level of resolution, numerous neuroimaging studies have now documented absence of the sixth nerve and even the misinnervation of the lateral rectus by fibers of the third nerve [23-27].

\section{Congenital Fourth Nerve Palsy and Brown Syndrome}

\section{Congenital Palsy of the Fourth Cranial Nerve}

Congenital fourth nerve palsies are particularly common in clinical practice, in part due to their small size and long circuitous anatomical course taken by the developing fourth cranial nerve [28]. The question then arises as to why this condition (unlike congenital sixth nerve palsy, which generally presents as Duane syndrome) is so infrequently associated with neuronal misdirection.

The clinical features of congenital fourth cranial nerve palsy, also referred to as trochlear nerve palsy or superior oblique palsy, are now well-established [29, 30]. Congenital superior oblique palsy is characterized by hypertropia of the involved eye that increases in the opposite field of gaze (ie, in adduction of the paretic eye), and during ipsilateral head tilt. Consequently, patients maintain a head tilt to the opposite side, enabling them to recruit utricular innervation to compensate for the hypertropia. Affected patients may present with apparently isolated inferior oblique muscle overaction (with minimal superior oblique underaction in the involved eye) and correlative extorsion, although they generally do not appreciate any correlative image tilt [31]. Despite its congenital origin, this condition may first come to medical attention during teenage or adult years, when diplopia, asthenopia, or headaches develop from a 
combination of spontaneous decompensation and superior rectus contracture [11]. The fusional amplitude of vertical deviation is significantly increased, reaching 16 to 30 prism diopters when normal values are 2-3 prism diopters [32]. Because of the large amplitude of vertical fusional vergence, the increase of vertical deviation induced by tilting the head of the patient toward the paretic eye (Bielschowsky head tilt test) is variable in congenital cases, and depends on factors such as fatigue and mental focus. Other associated findings in congenital fourth nerve palsy include longstanding head tilt on old photographs, facial asymmetry from contracture of the lower facial muscles, intermittent exotropia, and amblyopia in the involved eye [33].

Until recently, many authors pontificated that congenital superior oblique palsy resulted from a primary structural abnormality of the superior oblique muscle or its tendon [34]. Abnormalities of the superior oblique tendon were reported in $87 \%$ of congenital cases, and included absence, redundancy, abnormal insertion into the posterior Tenon's capsule, misdirection, and significant laxity [34-36]. MR imaging has shown that the degree of volume reduction of superior oblique muscle is more pronounced in congenital than in acquired cases $[37,38]$. Clark et al later used MR imaging to demonstrate that anatomical infradisplacement of the contralateral lateral rectus muscle could produce a constellation of clinical findings that is difficult to distinguish from those of congenital fourth nerve palsy [39].

In 2004, Jiang et al found ARIX gene polymorphisms in patients with congenital superior oblique muscle palsy [40]. $A R I X$ gene is expressed in the brainstem nuclei of both oculomotor and trochlear nerves, and mutations are also reported in some forms of congenital fibrosis of extraocular muscles (CFEOM) [40]. This genetic association was one of the initial hints that superior oblique palsy could be part of CCDD [6, 40, 41]. More recently, a study of high-resolution MR imaging by Yang et al found the trochlear nerve to be absent in $73 \%$ of 97 consecutive patients diagnosed with congenital superior oblique palsy $[42 \bullet \bullet, 43 \bullet \cdot]$. It now appears that absence of the fourth cranial nerve leads to secondary hypoplasia or atrophy of the superior oblique muscle with laxity or aplasia of its tendon. In the less common scenario in which trochlear innervation is preserved and the superior oblique muscle is normal and symmetric in volume, then the apparent congenital fourth nerve palsy is due to primary abnormalities of superior oblique muscle tendon or to extraocular muscle heterotopia [43••]. Alternatively, some cases with normally-developed fourth nerves could also represent early postnatal acquired palsies that cannot be differentiated from congenital palsies on clinical grounds.

In summary, congenital fourth nerve palsy probably comprises a number of different etiologies that primarily include primary neurogenic cases (now classified as CCDDs) with some cases less commonly resulting from a primary dysgenesis of the superior oblique tendon or trochlea.

\section{Congenital Brown Syndrome}

Brown syndrome is characterized by a limited active and passive elevation of the eye, which is maximal in adduction, a large exotropia in upgaze, and widening of the palpebral fissure in adduction [44]. Acquired cases result from inflammatory, traumatic, or surgical lesions of the superior oblique tendon or trochlea [45]. However, congenital Brown syndrome has long been attributed to structural abnormalities of the superior oblique muscle, tendon or trochlea $[1,44,45]$, which can explain the finding of restricted elevation in adduction on forced duction testing.

An innervational origin for some cases of congenital Brown syndrome was first suspected when electromyographic studies revealed paradoxical innervation of the superior oblique muscle [46, 47]. More recently, Kolling and colleagues and Neugebauer et al proposed that Brown syndrome might fall within the CCDDs [8•, 48]. In support of this hypothesis, Kaeser and colleagues found the ipsilateral fourth cranial nerve to be absent on MR imaging in 2 patients with unilateral congenital Brown syndrome [49•]. In both cases, the superior oblique muscle was neither hypoplastic nor atrophic despite the absence of the trochlear nerve, signifying the presence of an alternative innervation, by analogy with Duane syndrome [12, 49•]. Furthermore, the size of the involved superior oblique muscle remained constant during vertical eye movements, suggesting no physiological relaxation of the muscle in upgaze. This finding can be interpreted as an indirect sign of synkinetic innervation to the superior oblique muscle, again by analogy with Duane syndrome wherein the diameter of lateral rectus muscle remains constant during adduction and abduction [12].

If Brown syndrome is considered in the context of a CCDD, then an anomalous innervation of the superior oblique muscle by fibers of the third cranial nerve intended either for the medial rectus and/or inferior oblique muscle has to be presumed (Table 2). A co-innervation of the superior oblique and medial rectus muscles is not implausible, as these 2 muscles lie in closer anatomic proximity than the medial and lateral rectus muscles, which are known to be co-innervated in Duane syndrome. Co-contraction of superior oblique with either the medial rectus or inferior oblique muscles could produce a limitation of elevation that is most apparent in adduction, as well as other features of congenital Brown syndrome. The widening of the lid fissure frequently noticed during adduction in congenital Brown syndrome can be explained by the fact that both oblique muscles have their functional origin anterior to the eye equator, and thus 
Table 2 Proposed mechanisms and evidence for congenital cranial dysinnervation in congenital Brown syndrome

Mechanisms (1) Absence of the trochlear nerve and misinnervation of the superior oblique muscle by fibers of the third nerve intended for the medial rectus and/or inferior oblique muscle, inducing cocontraction of the muscles [8•, 48, 49•].

(2) Absence of innervation of the superior oblique muscle by the trochlear nerve inducing secondary structural changes of the superior oblique muscle and tendon with increased stiffness [50•].

Evidence (1) Contraction of superior oblique muscle on intended elevation in adduction [46, 47].

(2) Absence of the fourth nerve [49•].

(3) Normal superior oblique muscle despite absence of the fourth nerve (ie, necessitating misinnervation) [49•].

(4) Superior oblique muscle hypoplasia (ie, compatible with absence of normal innervation without misinnervation) [50•].

(5) Associations with other CCDD (Duane, congenital ptosis, congenital superior oblique palsy) [50•].

their simultaneous contraction will pull the eye outwards and retract the lids. The absence of significant ocular torsion is explained by the mutual cancellation of torsional action of both oblique muscles (superior oblique muscle intorts the eye, while inferior oblique muscle extorts it). A coincidental innervation of the superior oblique muscle by fibers intended for the medial rectus would also explain the depression of the eye in adduction present in some patients [8•, 48]. The associated exotropia in upgaze and persistent restriction of passive eye movement arise from contracture of the superior oblique muscle $[5,8 \bullet]$.

It has also been proposed that dysinnervation of the superior oblique muscle can lead to dysgenesis of the superior oblique muscle in the region of the trochlea [50•]. In their recent publication, Ellis and colleagues described coincident superior oblique hypoplasia and other signs of aberrant innervation in patients with congenital Brown syndrome [50•]. To explain their findings, the authors invoked a combined neurogenic and mechanical theory for both congenital superior oblique palsy and congenital Brown syndrome but without paradoxical innervation [50•]. According to the authors, the absence of the normal innervation of the superior oblique muscle by the trochlear nerve induces secondary abnormal development of the superior oblique muscle, tendon and/or trochlea. This abnormal development may take 1 of 2 forms: either a hypoplastic superior oblique
Fig. 1 Consequences of the congenital absence of the trochlear nerve with or without paradoxical innervation of the superior oblique muscle

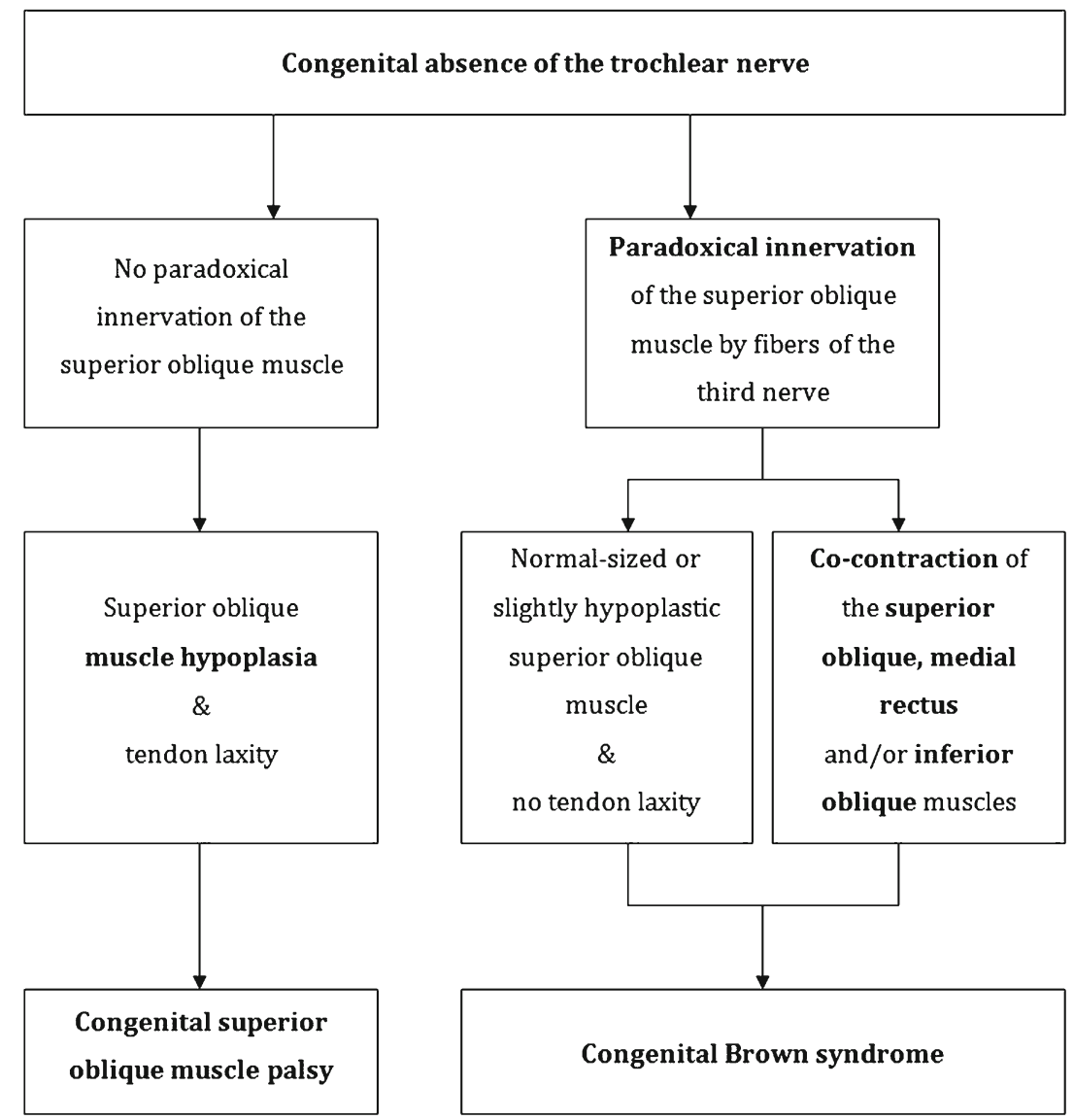


muscle with lax tendon, thus causing congenital superior oblique palsy, or a significant fibrosis or abnormal insertion of the superior oblique tendon, resulting in congenital Brown syndrome [50 $]$. This neurogenic/mechanical theory allows that some patients with absent superior oblique innervation develop tendon laxity while others develop stiffness, but does not account for the normal size of the superior oblique muscle, which so frequently occurs in congenital Brown syndrome [49•].

Any single neuroanatomical origin for congenital Brown syndrome would fail to explain the markedly positive forced duction test that provides diagnostic confirmation and the natural history of spontaneous resolution that occurs in some cases [51]. Therefore, we believe it likely that, neurogenic mechanisms and structural dysgenesis can both give rise to this phenotype. Kaeser et al recently described a patient with bilateral congenital Brown syndrome who spontaneously improved on one side [52]. MR imaging showed the intracranial trochlear nerve to be absent only on the side of the persistent Brown syndrome. As in previously published cases [49•], the size of the superior oblique muscle was normal and symmetric, but the superior oblique muscle did not relax on upgaze on the side of the persisting Brown syndrome, while it did on the resolved side. This case illustrates that congenital Brown syndrome can have a multiplicity of causes (involving both anatomic and neurogenic factors) even in the same patient. Those cases of Brown syndrome resulting from primary structural abnormalities of the superior oblique muscle, tendon, or trochlea seem to have the potential for spontaneous improvement related either to natural growth or to the repetitive elevation of the eye induced by the contraction of the superior rectus muscle. On the other hand a dysinnervational Brown syndrome would be expected to persist throughout life.

\section{Conclusions}

In analogy with the physiopathology of Duane syndrome, some cases of congenital Brown syndrome may represent a dysinnervation syndrome in which the absence of the trochlear nerve is accompanied by anomalous innervation and/or structural dysgenesis of the superior oblique muscle/trochlea complex (Fig. 1). Such an innervational origin to explain some cases of congenital Brown syndrome is supported by clinical and neuroimaging evidence at a number of levels: electromyographic studies showing paradoxical innervation of the superior oblique muscle [46, 47], absence of the trochlear nerve, on MR imaging without superior oblique muscle hypoplasia or atrophy, and absence of physiologic relaxation of the superior oblique muscle in upgaze [49•]. However, histologic confirmation of paradoxical innervation of the superior oblique muscle through fibers of the third cranial nerve has not been obtained. It is probable that some cases, especially those with spontaneous resolution, result from primary structural abnormalities of the superior oblique muscle, tendon, or trochlea.

Many intriguing questions remain about the pathogenesis of the CCDDs as they relate to these 2 overlapping conditions. First, their underlying etiology remains unknown, especially in sporadic cases. Do they result primarily from genetic factors [40] or from thromboembolic causes, as recently proposed by Robert and Parsa [21•]? Second, why is anomalous innervation more common in the setting of sixth than in fourth cranial nerve dysgenesis? Could occult synkinesis (in the form of dysinnervation from the superior rectus muscle to the paretic superior oblique muscle, for example) large fusional amplitudes and gradual development of ipsilateral superior rectus muscle contracture that often accompanies this condition? If so, then the adherence to a structural etiology for congenital fourth nerve palsy and congenital Brown syndrome may only be due to the incomplete elucidation of their neurodevelopmental etiology, similar to our early thinking about Duane syndrome. Finally, this analysis begs the question of whether similar mechanisms of neural dysgenesis can produce dysinnervation at the cortical level, giving rise to a different group of disorders characterized by misinnervation of afferent visual pathways (albinism, achiasmia, infantile esotropia). Some of these conditions have been found to overlap with the CCDD at the cellular and molecular level [53]. As the genetic and molecular causes of different forms of cranial dysinnervation become more clearly elucidated, these clinically-disparate conditions will inevitably become more unified.

Acknowledgment Supported in part by a grant from Research to Prevent Blindness, Inc.

Conflict of Interest Pierre-François Kaeser declares that he has no conflict of interest.

Michael C. Brodsky declares that he has no conflict of interest.

\section{References}

Papers of particular interest, published recently, have been highlighted as:

- Of importance

-• Of major importance

1. Brown HW. Congenital structural muscle anomalies. In: Allen J, editor. Strabismus ophthalmic symposium. St Louis, MO: C.V. Mosby; 1950. p. 205-36.

2. Harley RD, Rodrigues MM, Crawford JS. Congenital fibrosis of the extraocular muscles. Trans Am Ophthalmol Soc. 1978;76:197226.

3. Brodsky MC. Hereditary external ophthalmoplegia synergistic divergence, jaw winking, and oculocutaneous hypopigmentation: a 
congenital fibrosis syndrome caused by deficient innervation to extraocular muscles. Ophthalmology. 1998;105:717-25.

4. Brodsky MC. The doctor's eye: seeing through the myopathy of congenital ptosis. Ophthalmology. 2000;107:1973-4.

5. Gutowski NJ, Bosley TM, Engle EC. The congenital cranial dysinnervation disorders. Neuromuscul Disord. 2003;13:573-8.

6. Traboulsi EI. Congenital cranial dysinnervation disorders and more. J AAPOS. 2007;11:215-7.

7. Pieh C, Lagrèze WA. Congenital cranial dysinnervation disorders. Ophthalmology. 2007;104:1083-95.

8. - Neugebauer A, Fricke J. Congenital cranial dysinnervation disorders: facts and perspectives to understand ocular motility disorders. In: Lorenz B, Brodsky MC, editors. Essentials in ophthalmology:pPediatric ophthalmology, neuro-ophthalmology, genetics. Berlin, Heidelberg: Springer-Verlag; 2010. p. 83-7. The authors present both theoretical arguments and critical analysis of a large series of 87 cases of congenital Brown syndrome leading to consider congenital Brown syndrome as a CCDD.

9. Oystreck DT, Engle EC, Bosley TM. Recent progress in understanding congenital cranial dysinnervation disorders. J NeuroOphthalmol. 2011;31:69-77.

10. Assaf AA. Congenital innervation dysgenesis syndrome (CID)/ congenital cranial dysinnervation disorders (CCDDs). Eye. 2011;25:1251-61

11. Brodsky MC. Ocular motor nerve palsies in children. In: Pediatric neuro-ophthalmology. 2nd ed. New York: Springer; 2010. p. 253308.

12. Yüksel D, de Xivry JJ O, Lefèvre P. Review of the major findings about Duane retraction syndrome (DRS) leading to an update form of classification. Vision Res. 2010;50:233447.

13. Heuck G. Über angeborenen vererbeten Beweglichkeitsdefect der Augent. Klin Monatsbl Augenheilkd. 1879;17:253.

14. Bielschowsky A. Lectures on motor anomalies. Hanover, NH: Dartmouth College Publications; 1943/1956.

15. Türk S. Bemerkungen zu einem Fall von Retraktion des Auges. Centralbl Pract Augenheilkd. 1899;23:14.

16. Hoyt WF, Nachtigaller H. Anomalies of ocular motor nerves: neuroanatomic correlates of paradoxical innervation in Duane's syndrome and related congenital ocular motor disorder. Am J Ophthalmol. 1965;60:443-8.

17. Breinin GM. Electromyography: a tool in ocular and neurologic diagnosis. II. Muscle palsy. Arch Ophthalmol. 1957;57:165-75.

18. Matteuci P. I difetti congenti di abduzione con particolare riguardo alla pathogenesis. Rassegna Ital Ottalmologia. 1946;15:345-80.

19. Hotchkiss MG, Miller NR, Clark AW, Green WR. Bilateral Duane's retraction syndrome. A clinical-pathologic case report. Arch Ophthalmol. 1980;98:870-4.

20. Miller NR, Kiel SM, Green WR, et al. Unilateral Duane's retraction syndrome (TypI). Arch Ophthalmol. 1982;00:1468-72.

21. Robert MP, Parsa CF. Thromboembolism and congenital malformations: from Duane syndrome to Thalidomide embryopathy. Arch Ophthalmol. 2012;10:1-9. The authors propose that thromboembolism and focal cerebral hypoperfusion could cause Duane retraction syndrome and other congenital malformations, as an alternative to genetic mutations.

22. Kang NY, Demer JL. Comparison of orbital magnetic resonance imaging in Duane syndrome and abducens palsy. Am J Ophthalmol. 2006;142:827-34.

23. Parsa CF, Grant E, Dillon WP, du Lac S, Hoyt WF. Absence of the abducens nerve in Duane syndrome verified by magnetic resonance imaging. Am J Ophthalmol. 1998;125:399401.

24. Oskurt H, Basak M, Oral Y, et al. Magnetic resonance imaging in Duane's retraction syndrome. J Pediatr Ophthalmol Strabismus. 2003;40:19-22.
25. Kim HJ, Hwang JM. Presence of the abducens nerve according to the type of Duane's retraction syndrome. Ophthalmology. 2005;112:109-13.

26. Demer JL, Clark RA, Lim DK, Engle EC. Magnetic resonance imaging evidence for widespread orbital dysinnervation in dominang Duane's retraction syndrome linked to DURS2 locus. Invest Ophthalmol Vis Sci. 2007;48:194-202.

27. Demer JL, Clark RA, Lim DK, Engle EC. Magnetic resonance imaging of innervational and extraocular muscle abnormalities in Duane-radial-ray syndrome. Invest Ophthalmol Vis Sci. 2007;48:5505-11.

28. Holmes JM, Mutyala S, Mous TL, et al. Pediatric third, fourth, and sixth nerve palsies: a population-based study. Am J Opthtalmol. 1999;127:388-92.

29. Kolling GH. Diagnostik und operative Korrektur von Vertikal- und Zyklodeviationen bei Störungen schräger Augenmuskeln. DosisWirkungsbeziehung verschiedener Eingriffe. Giessen: Habilitationsschrift; 1986.

30. Steffen J, Kolling GH. Heterotopie. In: Kaufman H, Steffen H, editors. Strabismus. 4th ed. Stuttgart: Thieme; 2012. p. 247.

31. von Noorden GK, Murray E, Wong SY. Superior oblique paralysis. A review of 270 cases. Arch Ophthalmol. 1986;104:1771-6.

32. Mottier ME, Mets MB. Vertical fusional vergences in patients with superior oblique palsies. Am Orthopt J. 1990;40:88-93.

33. Wallace DK, von Noorden GK. Clinical characteristics and surgical management of congenital absence of the superior oblique tendon. Am J Ophthalmol. 1994;118:63-9.

34. Helveston EM, Krach D, Plager DA, Ellis FD. A new classification of superior oblique palsy based on congenital variations in the tendon. Ophthalmology. 1992;99:1609.

35. Plager DA. Traction testing in superior oblique palsy. J Pediatr Ophthalmol Strabismsus. 1990;27:136.

36. Plager DA. Tendon laxity in superior oblique palsy. Ophthalmology. 1992;99:1032.

37. Sato M. Magnetic resonance imaging and tendon anomaly associated with congenital superior oblique palsy. Am J Ophthalmol. 1999;127:379.

38. Sato M, Yagasaki T, Kora T, Awaya S. Comparison of muscle volume between congenital and acquired superior oblique palsies by magnetic resonance imaging. Jpn J Ophthalmol. 1998;42:466.

39. Clark RA, Miller JM, Rosenbaum AL, Demer JL. Heterotopic rectus muscle pulleys or oblique muscle dysfunctionl. J AAPOS. 1998;2:17-25.

40. Jiang Y, Matsuo T, Fujiwara H, et al. ARIX gene polymorphisms in patients with congenital superior oblique muscle palsy. Br J Ophthalmol. 2004;88:263-7.

41. Traboulsi EI. Congenital abnormalities of cranial nerve development: overview, molecular mechanisms, and further evidence of heterogeneity and complexity of syndromes with congenital limitation of eye movements. Trans Am Ophthalmol Soc. 2004;102:373-89.

42. • Kim JH, Hwang JM. Absence of the trochlear nerve in patients with superior oblique hypoplasia. Ophthalmology. 2010;117:220813. The authors used a very high-resolution cranial nerve MRI technique allowing visualization of the trochlear nerve in $100 \%$ of cases to show that the trochlear nerve was absent in patients with superior oblique hypoplasia. Based on that observation, they suggested that congenital superior oblique palsy with superior oblique hypoplasia should be classified as a CCDD.

43. •• Yang HK, Kim JH, Hwang JM. Congenital superior oblique palsy and trochlear nerve absence. A clinical and radiological study. Ophthalmology. 2012;119:170-7. In this study, a large series of 97 consecutive patients diagnosed with congenital superior oblique palsy were studied with cerebral MRI to evaluate the presence of the trochlear nerve. The trochlear nerve was absent on the affected side in $73 \%$ of cases, consistent with a CCDD. 
44. Parks MM, Brown M. Superior oblique tendon sheath syndrome of Brown. Am J Ophthalmol. 1975;79:82-6.

45. Wilson ME, Eustis HS, Parks MM. Brown's syndrome. Surv Ophthalmol. 1989;34:153-72.

46. Papst W, Stein HJ. Etiology of the superior oblique tendon sheath syndrome. Klin Monatsbl Augenheilkd. 1969;154:506-18.

47. Ferig-Seiwerth F, Celic M. A contribution to the knowledge of superior oblique tendon sheath syndrome (Brown's syndrome). Orthoptics. Proceedings of the Second International Orthoptic Congress, Amsterdam, May 11-13. Excerpta Medica. 1971;1972:354-9.

48. Kolling G, Rohde S, Kress B. Congenital Brown's syndrome is caused by missing fourth cranial nerve in some cases. Presented at the 32nd Meeting of the European Strabismological Association, Munich, Germany, September 7-10, 2008.

49. - Kaeser PF, Kress B, Rohde S, Kolling G. Absence of the fourth cranial nerve in congenital Brown syndrome. Acta Ophthalmol. 2012;90:e310-3. In this study, MR imaging showed that trochlear nerve was absent in 2 patients with congenital Brown syndrome, while superior oblique muscle was normal in size (ie, not hypoplastic) and did not relax as it should in upgaze. This study adds an anatomical support to consider some cases of congenital Brown syndrome as CCDD.

50. • Ellis FJ, Jeffery AR, Seidman DJ, Sprague JB, Coussens T, Schuller J. Possible association of congenital Brown syndrome with congenital cranial dysinnervation disorders. J AAPOS. 2012;16:558-64. The authors propose that congenital superior oblique palsy and Brown syndrome could both be secondary to an abnormal development of the trochlear nerve resulting in secondary physical changes of the superior oblique muscle, tendon, or trochlea.

51. Dawson E, Barry J, Lee J. Spontaneous resolution in patients with congenital Brown syndrome. J AAPOS. 2009;13:116-8.

52. Kaeser PF, Maeder P, Klainguti G. Absence of the fourth cranial nerve in persistent congenital Brown syndrome [poster POS2520]. 2nd World Congress of Pediatric Ophthalmology and Strabismus, Milano, Italy, September 7-9, 2012.

53. Khan AO, Shinwari J, Al Sharif L, et al. Infantile esotropia could be oligogenic and allelic with Duane retraction syndrome. Mol Vis. 2011;17:1997-2002. 